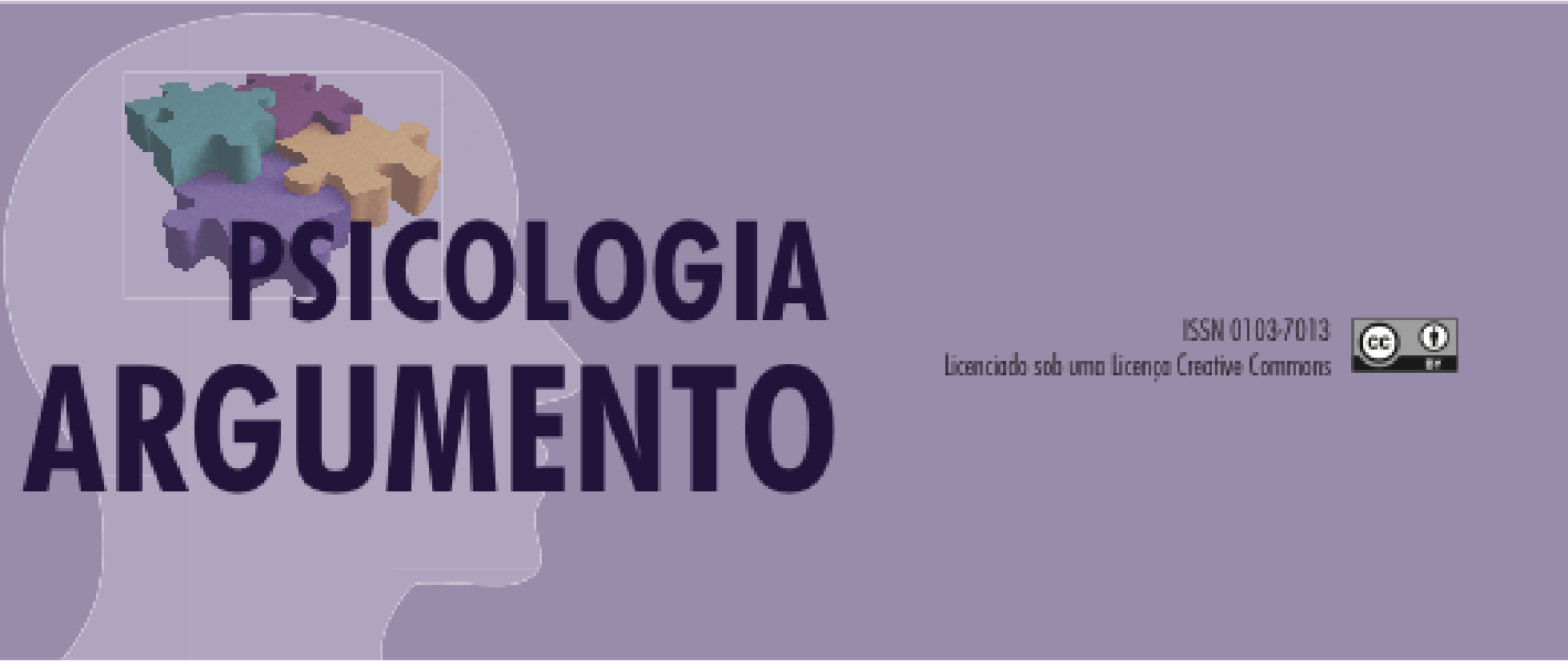

doi 10.7213/psicol.argum.33.082.AO02

\title{
Responsabilização $x$ Responsabilidades: 0 adolescente autor de ato infracional e a redução da maioridade penal
}

Accountability $\mathrm{x}$ responsibly: the adolescent authors of infraction acts and reducing the full legal age.

Beatriz Gomes Vaz ${ }^{[a]}$, Janice Strivieri Souza Moreira ${ }^{[b]}$

[a] Psicóloga especialista em Psicologia Jurídica pela Pontifícia Universidade Católica do Paraná. Curitiba - PR Brasil. beatriz.gvaz@hotmail.com

[b] Psicóloga, professora dos cursos de graduação em Psicologia e especialização em Psicologia Jurídica na Pontifícia Universidade Católica do Paraná e mestre em Educação. Curitiba - PR - Brasil.

janice.moreira@pucpr.br

\section{Resumo}

O presente artigo expõe a temática do adolescente autor de ato infracional e sua responsabilização, especialmente no que se refere ao clamor da sociedade pela redução da maioridade penal. Pesquisas revelam que aproximadamente $90 \%$ da opinião pública se diz favorável à proposta reducionista, fato que merece destaque no sentido de compreender os aspectos envolvidos neste posicionamento absolutamente relevante e os seus desdobramentos na instância legislativa e social. Constata-se que tais propostas 
remetem a uma visão linear na qual o contexto em que o jovem está inserido é desconsiderado e buscamse apenas soluções imediatistas e desconexas. Além disso, a responsabilidade da própria sociedade na garantia dos direitos fundamentais da população infanto-juvenil parece estar sendo negada ou dissimulada no teor deste pedido. Através de uma revisão da literatura e análise crítica dos fatos, busca-se contextualizar a problemática de exclusão e vulnerabilidade social em que vivem os jovens brasileiros. É imprescindível a sociedade reconhecer que a prática de atos infracionais por adolescentes, ainda que tenha seu arbítrio, é essencialmente uma problemática social. Portanto, há necessidade urgente dos atores responsáveis pelo cumprimento da Doutrina da Proteção Integral - família, Estado e sociedade assumirem seus papeis. Caso contrário, a redução da idade penal permanecerá como uma solução simples e muito atraente, disfarçando todas as reponsabilidades daqueles que deveriam se implicar incondicionalmente com a garantia dos direitos das crianças e adolescentes brasileiros. [P]

Palavras-chave: Adolescente. Delinquência Juvenil. Marginalização Social. Defesa da Criança e do Adolescente..

\begin{abstract}
The present study exposes about the adolescent authors of infraction acts and accountability, especially in relation to the clamor of society by reducing the full legal age. Researches demonstrate that about 90\% of public opinion is favor for the reduction of the full legal age and this fact merits highlights in order to understand the aspects involved in this absolutely relevant positioning and yours developments in legislative and social instance. It is noted this proposition refer to a linear view in which the adolescent context is disregarded and is looking for only short-sighted and disconnected solutions. Moreover, the society responsibility in ensure the fundamental rights of children and adolescents seems to be denied or disguised on the content of this request. Through the literature review and critical analysis of the facts, the purpose is to contextualize the problem of exclusion and vulnerability experienced by the young Brazilian. It is essential to society recognize that practice of illegal act by adolescents, although it has its will, is essentially a social problem. Therefore, there is an urgent need of actors responsible for compliance with Doctrine of Integral Protection - family, State and society assumes their roles. Otherwise, the reduction of the full legal age remains a very attractive and simple solution, disguising all the responsibilities of those who should be involved unconditionally with the guarantee of the Brazilian children and adolescents rights. [K]
\end{abstract}

Keywords: Adolescent. Juvenile Delinquency. Social Marginalization. Child Advocacy.

\title{
Introdução
}

A temática do adolescente em conflito com a lei é intrigante e complexa, tendo em vista que a prática de atos infracionais por jovens envolve uma diversidade de fatores, além de diversos posicionamentos que não podem ser contemplados somente sob uma ótica ou disciplina. A problemática adquire maior complexidade especialmente quando se trata da discussão referente à redução da idade de responsabilização penal brasileira. Atualmente, é notório seu destaque na esfera legislativa devido à Proposta de Emenda à Constituição (PEC) 171-1993 que avançou no trâmite da câmara dos deputados e, no momento, aguarda a apreciação do Senado Federal.

Pesquisas revelam que aproximadamente $90 \%$ da opinião pública se diz favorável ao rebaixamento da maioridade penal, fato que merece destaque no sentido de compreender os aspectos envolvidos neste posicionamento absolutamente relevante e os seus desdobramentos na instância legislativa e social. Diante deste intenso clamor da sociedade pela responsabilização dos adolescentes, questiona-se: quais responsabilidades da própria sociedade estariam sendo negadas e dissimuladas no teor deste apelo?

O Plano Nacional de Atendimento Socioeducativo elaborado pela Secretaria de Direitos Humanos da Presidência da República (Brasil, 2013) revelou que no ano de 2011 a população adolescente somava pouco mais de 20 milhões de pessoas, sendo que $0,094 \%$ 
cumpria medida socioeducativa, ou seja, menos de um adolescente em cada mil. Apesar de aparentemente ser um número reduzido, em números absolutos, havia 19.595 adolescentes cumprindo medida em regime fechado e 88.022 , em meio aberto, o que não parece tão insignificante assim.

Ainda de acordo com o documento, a interpretação do aumento significativo das taxas de restrição e privação de liberdade e dos atos infracionais relacionados ao tráfico de drogas, propõe que os principais motivos de internação dos adolescentes estão diretamente relacionados à vulnerabilidade social a que estão expostos. Além disso, o crescimento das medidas de privação de liberdade para casos considerados de baixa gravidade foi relacionado mais a uma resposta aos apelos da sociedade pela redução da maioridade penal do que à realidade em si.

O Índice de Homicídios na Adolescência (IHA) divulgado pelo Fundo das Nações Unidas para a Infância (UNICEF) em parceria com a Secretaria de Direitos Humanos da Presidência da República (SDH) traz informações de fundamental importância no que se refere aos adolescentes que são vítimas da violência. Apesar das infrequentes notificações da mídia, os dados são absolutamente alarmantes. De acordo com o relatório, os homicídios representam $45,2 \%$ das mortes de adolescentes brasileiros, enquanto o mesmo índice para a população total é de 5,1\%. Em relação aos riscos por gênero, cor ou raça, a probabilidade de um adolescente do sexo masculino ser vítima de homicídio é 11,5 vezes maior do que para as adolescentes do sexo feminino, enquanto o risco para os negros é quase três vezes maior em relação aos brancos (Melo \& Cano, 2012).

Isso demonstra o quanto a população infanto-juvenil brasileira representa a parcela mais exposta às violações de direitos. $\mathrm{O}$ adolescente de hoje traz consigo todos os estigmas que lhe foram atribuídos ao longo da história cujo reflexo ainda se propaga através de alguns segmentos da sociedade. Além disso, enfrenta os diversos obstáculos impostos por lacunas de natureza pessoal e social, especialmente daqueles que deveriam garantir seus direitos fundamentais, tais como o poder público, a sociedade e sua própria família.

Diante da relevância dessa temática, dos alarmantes dados apontados acerca de tal realidade e da efervescente discussão acerca da redução da idade penal, o presente artigo propõe uma revisão da literatura objetivando analisar o tema a partir de um aporte teórico sistêmico, o qual pressupõe a importância de contextualizar, ampliar e buscar relações entre diferentes perspectivas com a intenção de evidenciar a complexidade presente na problemática. Sendo assim, é imprescindível compreender tanto os aspectos envolvidos no posicionamento reducionista quanto seu contraponto que envolve as questões da exclusão e vulnerabilidade social em que vivem os jovens brasileiros a partir de uma perspectiva crítica. Portanto a seleção da literatura baseou-se nas temáticas relacionadas ao adolescente autor de ato infracional e sua responsabilização, perpassando sobretudo entre os campos da psicologia e do direito. Além disso, foram consultados relatórios com dados atualizados e resultantes de pesquisas realizadas em âmbito nacional especialmente sobre a socioeducação.

Concepção social sobre o adolescente autor de ato infracional e sua responsabilização

A trajetória enfrentada pela população infanto-juvenil brasileira durante os séculos foi marcada por exclusão e marginalização social. Ainda que novos paradigmas 
legislativos e assistenciais tenham surgido, a mudança estrutural de reconhecimento e garantia dos seus direitos fundamentais é um processo lento e complexo.

Em se tratando dos adolescentes que cometeram ato infracional, a mudança de paradigmas parece demandar transformações sociais e culturais ainda mais profundas. Tendo em vista os movimentos sociais iniciados ao final da década de 80 e início da década de 90, é possível considerar que a sociedade brasileira ainda está em momento de transição no sentido de assimilar os dispositivos legais preconizados especialmente pelo Estatuto da Criança e do Adolescente (ECA).

Além disso, conforme descrito por Volpi (2001), observa-se que a sociedade em geral tem maior facilidade para mobilizar-se sempre que se trata da defesa de vítimas perante seus possíveis agressores. $\mathrm{O}$ apelo emocional que constitui o imaginário dos indivíduos parece ser mais forte e causar maior sensibilização quando se identifica claramente alguém como vítima de uma determinada situação. Em contrapartida, reconhecer no agressor um cidadão parece configurar um exercício difícil e, muitas vezes, para alguns, inapropriado. Os adolescentes autores de ato infracional constituem uma categoria que não encontra eco para a defesa de seus direitos, pois, pelo fato de terem praticado tal ato são desqualificados como Sujeitos de Direitos e rotulados como infratores, delinquentes, perigosos e outros adjetivos estigmatizantes que constituem uma face da violência simbólica.

De acordo com Prates (2001), a intolerância social para com o adolescente em conflito com a lei tem repercussão das mais diversas formas. Nestas estão compreendidos desde os diálogos populares que atribuem a esses adolescentes à condição de marginais perigosos e cruéis, até mesmo políticas públicas que acabam por mobilizar movimentos de exclusão com a finalidade de manter esta parcela indesejada da população afastada do meio social.

Volpi (2001) apresenta sucintamente o resultado de seus estudos relativos aos três mitos que condicionam a compreensão da prática de atos infracionais por adolescentes.

O primeiro mito se refere ao hiperdimensionamento da temática. Notícias transmitidas nos veículos de comunicação social, opiniões explicitadas por autoridades e profissionais que atuam na área e até mesmo o cidadão comum quando perguntado sobre a questão afirmam categoricamente que são milhões os adolescentes que cometem atos infracionais e que a violência juvenil cresce a cada dia. No entanto, segundo o autor, não existem dados confiáveis que permitam observar a evolução do fenômeno uma vez que não há qualquer pesquisa de âmbito nacional que sustente tal afirmação. Portanto, quando se trata do aumento da violência cometida por adolescentes, está se expressando sensações e não uma opinião baseada em dados comprovadamente reais (Volpi, 2001).

Segundo Teixeira (2013), é importante ressaltar que problematizar o superdimensionamento da participação real da adolescência nos índices de criminalidade não significa desresponsabilizar o adolescente autor de ato infracional. Tendo em vista que a legislação pertinente representada pelo Estatuto da Criança e do Adolescente constitui um instrumento com duplo caráter de responsabilização - sancionatório e educacional - no qual a aplicação de medidas socioeducativas é uma resposta à conduta infracional praticada por adolescentes prevista em lei, mas possui especialmente um caráter educativo visando sua reinserção da sociedade.

O segundo mito é o da periculosidade dos adolescentes, os quais tenderiam a praticar delitos cada vez mais graves. Os estudos referidos pelo autor (Volpi, 2001) na 
época da publicação indicavam que os delitos cometidos pelos adolescentes eram em sua maioria crimes contra o patrimônio.

Atualmente, de acordo com o Panorama Nacional de Execução de Medidas Socioeducativas de Internação do ano de 2012 (Conselho Nacional de Justiça, 2012), verifica-se que os atos infracionais mais praticados permanecem caracterizando os crimes contra o patrimônio, tais como roubo e furto, sendo que o índice representa $43 \%$ do total de tipificações.

Ainda segundo proposta de Volpi (2001), o terceiro mito, frequentemente verificado, refere-se à irresponsabilidade do adolescente. Sustentando a crença de que o mesmo estaria mais propenso à prática de atos infracionais porque a legislação seria muito branda em relação à punição, o autor afirma que:

Neste caso, ocorre uma confusão entre inimputabilidade penal e impunidade. $\mathrm{O}$ fato de um adolescente ser inimputável penalmente não o exime de ser responsabilizado com medidas socioeducativas, inclusive com a privação de liberdade por até três anos. A ideia de que o agravamento das penas reduziria a prática de delitos não foi comprovada por nenhuma sociedade, nem mesmo por aquelas que adotam a pena capital (p. 16).

Sendo assim, percebe-se como uma das possíveis expressões de tais mitos o clamor intenso pela redução da maioridade penal. De tempos em tempos, retoma com força na pauta nacional a questão do rebaixamento da idade de responsabilização penal. Visivelmente motivada por noticiários dos meios de comunicação, a discussão sobre este tópico volta à tona. Há quem defenda a severidade da lei apoiando a redução do limite da maioridade penal para dezesseis anos ou até em idade inferior.

A imensa maioria da população sustenta argumentos favoráveis, traduzindo sentimentos de revolta e indignação, especificamente diante de um fato noticiado exaustivamente pela mídia. Nestes momentos, nos quais a redução da idade penal retorna ao debate nacional, alguns legisladores se dedicam à elaboração ou retomada de Propostas de Emendas Constitucionais (PEC).

Diante do exposto, Teixeira (2013) elucida a respeito da produção da mentalidade social que consagra o adolescente autor de ato infracional como um responsável importante pelo agravamento da criminalidade e requisita o rebaixamento da sua idade de responsabilização penal:

O clamor popular por segurança e paz públicas associado a essa mentalidade dominante que desconhece a multideterminação do fenômeno da violência e de sua expressão mais descarada - a criminalidade - favorecem o estabelecimento de bode expiatório para qual o adolescente tem um bom figurino: está, historicamente, associado a rebeldia, contestação de autoridade, inconformismo ante a desigualdade social, porque querem consumir tudo aquilo que passa diante de seus olhos e está associado a felicidade, bem-estar, com um ícone de identidade. Portanto o sentimento de vulnerabilidade dos cidadãos favorece uma mentalidade que se caracteriza por vingança social e práticas repressivas e é nesse contexto que se insere a defesa da redução da idade penal (p. 20).

Partindo deste princípio, é possível identificar três grandes domínios os quais edificam a construção social que envolve a percepção e entendimento da prática de atos infracionais por adolescentes e sua responsabilização: a mídia, a imensa opinião pública favorável e o poder legislativo. Observa-se que esta construção tanto é determinada quanto reproduz condicionantes históricos e socioculturais. Ressalta-se que embora novos paradigmas demonstrem um movimento de transformação social, muitos mitos e 
concepções persistem na direção de exclusão e marginalização dos jovens em conflito com a lei.

A seguir serão abordados os três domínios identificados na literatura pesquisada e de que forma subsidiam a concepção social que envolve os adolescentes autores de atos infracionais e sua responsabilização..

\section{Mídia}

O Guia de Referência para Cobertura Jornalística (Andi, 2012) referente à temática do adolescente em conflito com a lei do ano de 2012, publicado pela Agência de Notícias dos Direitos da Infância em parceria com a Secretaria de Direitos Humanos da Presidência da República traz informações importantes relacionadas ao tópico em questão.

Ainda que historicamente a imprensa tenha realizado importante função no que se refere à proteção dos direitos humanos, denunciando violações e fortalecendo o debate público em torno das formas de garanti-los e promovê-los, verifica-se que a matéria da infância e juventude neste âmbito ainda configura um desafio. Especialmente as questões relacionadas ao adolescente em conflito com a lei encontram-se em nível preocupante de invisibilidade, uma vez que só ganham destaque na mídia quando estão associadas a crimes graves, provocando distorções na percepção pública sobre o fenômeno (Andi, 2012).

Segundo Marques (2000), a mídia em geral não valoriza o tema relacionado aos adolescentes em risco social e jovens em conflito com a lei, porque não lhe traz retorno mercadológico evidente. É um mecanismo de produção como outro qualquer, pois é uma empresa antes de ser imprensa e, sendo assim, tem que sobreviver em um sistema de mercado.

Bocco (2009) destaca que neste momento o credo criminológico central dos veículos de comunicação é "a ideia da pena como rito sagrado para solução de todos os conflitos" (p. 125). No caso da infração juvenil, uma das crenças mais amplamente destacada está relacionada à redução da idade de responsabilização penal como solução irrefutável para a violência contemporânea. Toda vez que um jovem é autor de um delito que choca a população, a mídia dá ampla cobertura fortalecendo as ideias equivocadas da extrema periculosidade dos fatos e de que os jovens são autores de número expressivo de delitos.

Por outro viés, mas não menos importante, Macedo (2008) destaca que o "indivíduo, em várias épocas de sua vida, obtém algumas normas sociais através dos veículos de comunicação, os quais assumem um importante papel no complexo processo de socialização" (p.73). Especialmente na adolescência, período no qual é fundamental o pertencimento a um determinado grupo, a constituição grupal de valores e conceitos pode ser influenciada diretamente pela mídia. O autor salienta ainda que é evidente a influência desta como agente publicitário, na medida em que influencia comportamentos de jovens e adultos, incentivando o consumismo exacerbado e valorizando o ter sobre o ser.

Nota-se que a mídia se caracteriza por um instrumento muito contraditório. O mesmo veículo de comunicação - e o principal - que incentiva e reproduz o princípio do consumismo onde a felicidade e o valor se encontram no "ter", na aquisição financeira e no status social, é o mesmo que irá condenar severamente o jovem pela prática de ato 
infracional. No entanto, sabe-se que muitos destes adolescentes comentem delitos justamente buscando pertencer a este preceito tão difundindo e valorizado pela sociedade.

\section{Opinião pública}

Diante da literatura pesquisada identificam-se os principais argumentos utilizados pela sociedade na tentativa de justificar e sustentar a opinião favorável à redução da idade penal. Vale destacar que os autores que serão citados a seguir apresentam os pontos favoráveis da doutrina reducionista, mas estabelecem uma análise crítica de tais posicionamentos.

Primeiramente pontua-se que a referida população está constantemente manifestando sentimentos de insegurança diante do crescimento alarmante da violência. Nestes casos, muitas vezes associa-se o aumento da criminalidade à participação dos adolescentes, como se fossem um dos grandes responsáveis pelo agravamento dos crimes. Frente a esta problemática, acredita-se que o poder público se mostra ineficiente no combate e repressão da criminalidade (Prates, 2001). Nesse sentido, Macedo (2008) salienta que:

Apesar da problemática da violência juvenil trazer à tona a preocupação da sociedade, a necessidade de diminuir a idade limite para a responsabilização criminal é questionada, argumentando-se que as medidas socioeducativas existentes seriam eficazes se aplicadas adequadamente, respeitando-se os direitos humanos e a condição do adolescente como ser em desenvolvimento, capaz de reverter sua agressividade se bem orientado e auxiliado por profissionais competentes (p. 185).

Outra questão está centrada na utilização cada vez mais frequente de crianças e adolescentes pelo crime organizado, uma vez que estes são "imunes" a qualquer tipo de pena. Há uma verdadeira crença de que os jovens não são presos, pois têm proteção do ECA, dispositivo que, segundo a visão do senso comum, estimularia a impunidade (Macedo, 2008 \& Saraiva, 1999).

Em consonância com Saraiva (1999), nota-se que a proposta reducionista em nosso país está diretamente relacionada com a absoluta desconsideração (e não absoluta prioridade, como preconizado pela lei) para com o cumprimento das regras de responsabilização previstas no Estatuto da Criança e do Adolescente. Como já destacado, o ECA prevê e sanciona medidas de proteção e medidas socioeducativas que pretendem ser eficazes, as quais oferecem diversas alternativas de responsabilização, desde a advertência até a medida mais grave que impõe a restrição de liberdade ao adolescente autor de ato infracional. Sendo assim, como destacado por Macedo (2008), esta normativa garante efetiva resposta e proporcionalidade ao delito praticado.

O equívoco frequente entre as condições de inimputabilidade penal e impunidade, denuncia o desconhecimento dos dispositivos legais direcionados à infância e juventude por parte da população brasileira. Neste sentido, ignora-se o fato de que um adolescente com doze anos de idade, ainda que incluído no rol de inimputáveis penais, já pode ser responsabilizado por sua conduta inclusive através da privação de sua liberdade. Fato evidente de que a responsabilização prevista pelo ECA pode ser de fato rigorosa.

Outro posicionamento comumente compartilhado pela opinião pública refere-se à ideia de que no Brasil as leis são brandas e os direitos humanos só servem para defender "bandidos" (Arantes, 2013). Sendo que "em decorrência disso, brada-se aos quatro ventos como solução para o enfrentamento da criminalidade a redução da idade de 
responsabilização penal", por certo imaginando que lançando os jovens de dezesseis anos ou menos no falido sistema penitenciário brasileiro, se estará contribuindo para o resgate da cidadania nacional (Saraiva, 1999, p. 120).

A questão do sistema penitenciário merece destaque uma vez que a proposta reducionista revela um pensamento linear de encarceramento que parece desconsiderar a atual condição em que se encontram os presídios brasileiros. É preocupante e vale destacar que o clamor pela mudança legislativa estaria diretamente implicado na inclusão (ou exclusão) desta parcela de jovens no sistema penitencial, fadados ao atual encarceramento falho no sentido de recuperação e reinserção social.

Brito (2013) propõe "examinar o tema pelo avesso, trazendo a lume alguns dados referentes às condições do sistema penal brasileiro" (p. 16). A autora retrata a precária realidade em que se encontram as unidades prisionais, que não só fere abusivamente os direitos humanos, como também não promove a reinserção social. Destaca ainda dados alarmantes que apontam o Brasil como o $4^{\circ}$ país do mundo no que se refere ao encarceramento, sendo a taxa de reincidência de $70 \%$. Diante deste panorama, alguns dos questionamentos da autora se mostram fundamentalmente pertinentes: para que reduzir a maioridade penal, fazendo com que os adolescentes tomem contato com esta realidade? Depois de alguns anos neste sistema em condições degradantes, como os jovens serão reinseridos na sociedade?

Macedo (2008) afirma que "mesmo aqueles que são favoráveis ao recrudescimento das penas e da criminalização de condutas admitem que o sistema penitenciário não recupera cidadãos e serve apenas como depósito de indivíduos que são segregados da sociedade" (p. 198). Partindo desse princípio, se os presídios não recuperam os adultos, seriam eficazes na recuperação de jovens?

Finalmente, um dos argumentos mais proferidos pelo senso comum trata-se do direito político ao voto concedido aos adolescentes maiores de dezesseis anos. Acredita-se que se o jovem é capaz de escolher seus próprios governantes, da mesma forma, deve ser responsabilizado criminalmente, uma vez que demonstra discernimento para ambas as situações (Macedo, 2008).

Este posicionamento representa especialmente o caráter linear que reveste o clamor pela redução da maioridade penal. Ou seja, as manifestações da sociedade ocorrem de forma simplista e reducionista, sem considerar a real complexidade dos fatos. Vale destacar um posicionamento do Conselho Federal de Psicologia (2013) perante a referida questão:

Causa imensa preocupação o desconhecimento ou a distorção dos dados da realidade, a homogeneização dos sujeitos, a patologização e a criminalização das condutas dos adolescentes tudo isso em nome da "justiça", que vem sendo apresentada como sinônimo de punição e aprisionamento. Constata-se também uma tendência à individualização dos atos e culpabilização dos adolescentes, especialmente os pobres e negros, em uma visível manifestação de preconceitos, de violação dos direitos humanos e de mecanismos de exclusão (p. 5).

Diante do exposto, os argumentos utilizados pela opinião pública favorável à redução da maioridade penal evidenciam sua fragilidade e o quanto são passíveis de questionamento. É notória a necessidade de esclarecimento da sociedade em relação ao contexto legislativo e social no qual vivem as crianças e adolescentes brasileiros. Sendo assim, é possível construir discussões populares fundamentadas em elementos da realidade 
e que não se limitam ao pensamento reducionista e linear, mas que contemplam toda a complexidade desta problemática.

\section{Poder legislativo}

O poder legislativo brasileiro, aqui representado por seus parlamentares favoráveis ao rebaixamento da idade de responsabilização penal, constitui uma esfera importante na referida questão, tendo em vista que são os responsáveis pela formulação das leis que regulam o país. Deputados e senadores, movidos por convicções ou exclusivamente em resposta ao apelo popular e oportunismo, propõem o recrudescimento da lei através da redução da maioridade penal.

Real e Conceição (2013) apresentam uma análise sobre as representações sociais contidas nas Propostas de Emenda Constitucionais que tramitam na Câmara e no Senado Federal, as quais visam reduzir a maioridade penal vigente no Brasil. As autoras alertam que os discursos favoráveis à redução estão repletos de argumentos relacionados ao antigo Código de Menores, não só pelos termos utilizados - tais como "menor" e "delinquente" mas também por ignorar a existência da atual Doutrina de Proteção Integral.

O equívoco frequente entre as condições de inimputabilidade penal e impunidade também se faz presente nos argumentos dos parlamentares. Saraiva (1999) esclarece que inimputabilidade não implica em impunidade, "vez que estabelece medidas de responsabilização compatíveis com a condição de peculiar pessoa em desenvolvimento destes agentes" (p. 25). Complementando, Macedo (2008) destaca que a exclusão de responsabilidade penal não significa que os adolescentes autores de infrações não serão responsabilizados pessoal e socialmente por seus atos:

A fixação da idade penal em dezoito anos não se deve apenas a questões de política criminal, mas também em razão da comprovação técnico-científica de que, na adolescência, a passagem da infância para a vida adulta faz com que o indivíduo atravesse uma fase de profundas transformações e entre em conflito com os seus valores, sua personalidade, sua estrutura psicológica (p.196).

Segundo a autora, o objetivo de fixar a idade penal aos dezoito anos é justamente impedir que os adolescentes venham a cumprir pena em estabelecimento fechados, os quais prejudicariam sua formação e desenvolvimento.

Ainda que existam posicionamentos contrários, Saraiva (1999) observa que a tese reducionista, em principio, se faz inconstitucional. Considera-se que o direito determinado no art. 228 da Constituição Federal, que fixa a idade penal em dezoito anos, constitui cláusula pétrea, pois é inegável seu conteúdo de direito e garantia individual.

Questiona-se também, se tal proposta de redução da idade penal pode contrariar acordos internacionais dos quais o Brasil é signatário ou colocar o país na contramão da tendência das demais nações. Acredita-se que o exposto viola o dispositivo art. 41 da Convenção das Nações Unidas de Direito da Criança (Decreto n ${ }^{\circ} 99.710$ de 21 de novembro de 1990 que promulga a Convenção sobre os Direitos da Criança), no qual está implícito que os signatários não tornarão mais gravosa a lei interna de seus países, em face do contexto normativo da Convenção (Macedo, 2008 \& Saraiva, 2008).

Real e Conceição (2013) afirmam que os legisladores igualmente cometem equívocos neste sentido: 
A par dos argumentos reducionistas, esses defensores cometem equívocos também sobre questões de ordem temática ao aduzir que a maioria dos demais países adotou, em sua esfera jurídico-legal, uma rigidez no tocante à maioridade penal, quando isso se provou uma inverdade. O Brasil, além de atender seus compromissos internacionais, está em uníssono com a política adotada por muitos países (p. 669).

Como bem destaca Macedo (2008), é necessário que o poder público, antes de defender propostas reducionistas, discuta se as determinações da Constituição Federal e do ECA - que dispõe sobre o dever da família, do Estado e da sociedade em assegurar os direitos fundamentais das crianças e adolescentes com a absoluta prioridade - estão sendo efetivadas. Sendo assim, "o problema da criminalidade infanto-juvenil irá perdurar enquanto não forem combatidas as suas causas" (p.195).

Ao longo das últimas décadas, observa-se que a legislação brasileira possibilitou grandes conquistas em direção ao entendimento de que a população infanto-juvenil, independentemente de condições socioeconômicas ou eventual prática de ato infracional, é merecedora de proteção integral. Sendo assim, conforme Saraiva (1999) e Prates (2001), a proposta reducionista estaria na contramão da história e representaria um enorme retrocesso legislativo.

\section{Adolescente autor de ato infracional: da problemática social à possibilidade de mudança}

Fazer uma leitura sistêmica de um fenômeno pressupõe analisar a complexidade dos aspectos que o constituem. Para compreender o todo é imprescindível considerar o contexto no qual está inserido. Ao contrário do que o paradigma linear propõe - através de uma visão determinista de causa e efeito - o olhar sistêmico constitui um movimento no sentido de ampliação e busca de relações entre diferentes perspectivas.

A concepção social de alguns segmentos importantes da sociedade em relação à prática de atos infracionais por adolescentes e sua responsabilização remete a uma visão linear sobre o fenômeno. Todo o contexto no qual o jovem está inserido é desconsiderado e buscam-se apenas soluções imediatistas e desconexas no intuito de combater os efeitos desta problemática. Afinal, são somente os efeitos que acabam sendo reconhecidos através dos noticiários da mídia e não os graves fatores envolvidos na sua construção.

Desta maneira, "a opinião pública tem sido levada a olhar somente na ótica do crime, e assim, fica parecendo fácil resolver o problema" (Souza, 2007, p. 254), uma vez que as questões sociais têm sido cada vez mais consideradas como problemas dos indivíduos, especialmente daqueles que vivem em um contexto de violência e vulnerabilidade.

Neste caso, a visão do paradigma linear diz respeito à atribuição determinista do ato infracional ao jovem que o comete. Dessa forma, são atribuídas exclusivamente aos indivíduos, problemáticas de ordem essencialmente social. Não se pretende aqui uma tentativa de desconsiderar o arbítrio do jovem diante da prática de atos infracionais, mas propor uma reflexão a respeito de quais são as responsabilidades da sociedade nesse sentido.

Através do histórico de assistência social e legislação brasileira, pode-se considerar que houve intensa criminalização de indivíduos ou de determinados segmentos da sociedade ao longo dos séculos. Costa e Mandalozzo (2007) afirmam que os conflitos 
eram vistos sob a ótica da criminalidade, especialmente quando envolviam crianças e adolescentes oriundos de famílias com fracos laços de convivência entre seus membros ou em situação de abandono material e moral.

O apelo de Bocco (2009) vem ao encontro desta proposta e introduz o direcionamento a um olhar sistêmico diante da questão dos adolescentes em conflito com a lei:

A discussão sobre a juventude criminalizada diz respeito ao modo de subjetivação do contemporâneo e tem maior gravidade do que possamos perceber. Falar da infração juvenil não é falar de um fato isolado, muito pelo contrário. É analisar como funcionamos enquanto sociedade, como produzimos infâncias e juventudes desiguais, como criminalizamos os pobres, como organizamos o mundo do trabalho, do ensino, da cultura, como judicializamos as relações [...]. Reconhecer que a infração é fabricada socialmente nos leva a implicar-nos de forma efetiva com uma não reprodução desse modelo e com a criação de outras realidades e sujeitos [...] (p. 134).

A questão da prática de atos infracionais por adolescentes é um problema amplo, assim como qualquer outra problemática de ordem social. Volpi (2001) afirma que as teorias que estudam o ato infracional apontam para uma multidiversidade de fatores que $o$ produzem de forma complexa e de difícil isolamento.

Atualmente vivemos em uma sociedade caracterizada por um contexto político e econômico extremamente excludente. Desta maneira, situações que emergem na atual conjuntura brasileira são fatores que contribuem para que a população infanto-juvenil seja inserida num processo de falta de perspectivas (Souza, 2007 \& Prates, 2001).

Ainda de acordo com Souza (2007), as contradições sociais existentes na sociedade brasileira estão cada vez mais acentuando as condições de marginalidade da população que permanece com dificuldades de acesso a condições mínimas de sobrevivência e inclusão social. Desta forma, são marcados com o estigma da marginalidade cujo significado não pode ser confundido com um traço de personalidade.

Vale destacar a pesquisa para elaboração do Panorama Nacional sobre a execução das medidas socioeducativas de internação (Conselho Nacional Justiça, 2012) cujas porcentagens foram representativas no que se refere à questão do adolescente em conflito com a lei. Segundo o documento, os dados mais expressivos relacionados à tipificação dos atos infracionais foram os seguintes: em primeiro lugar, com alta representatividade de $36 \%$ está o roubo e em seguida, o tráfico de drogas totalizando $24 \%$ das tipificações.

As dificuldades de sobrevivência, ocasionadas por uma sociedade tão excludente, são incontestavelmente, causas de maior índice de criminalidade, já que "o mundo atual é desigual nas oportunidades que oferece e igualador nas ideias e nos costumes que impõe, pois convida todos para o banquete e fecha as portas no nariz das maiorias" (Prates, 2001, p. 24). Esta analogia descreve muito bem o contexto atual gerado especialmente pelo consumismo exacerbado o qual atinge da mesma forma todos os adolescentes, independentemente de suas condições econômicas e sociais. Frequentemente alguns jovens, tentando fazer parte deste padrão, que valoriza o "ter", acabam por cometer delitos buscando os recursos dos quais nunca tiveram acesso. Além disso, parecem estar atendendo à mensagem implícita que esses valores sociais imprimem, ou seja, não ter, impossibilita o pertencimento, exclui. 
Todos os seres humanos têm a necessidade de pertencimento. Muitas vezes estes adolescentes buscam, de forma equivocada, uma maneira de pertencer e vencer essas diferenças sociais que lhe atingem e lhe foram impostas desde muito cedo.

\title{
Responsabilidades previstas pelo Estatuto da Criança e do Adolescente
}

O Estatuto da Criança e do Adolescente, desde que foi sancionado, prevê as responsabilidades do Estado, da sociedade e da família com o futuro das novas gerações. Dentro deste novo paradigma e concepção, crianças e adolescentes são reconhecidos como sujeitos de direito, pessoas em condição peculiar de desenvolvimento e prioridade absoluta no que se refere às políticas públicas, incluindo a liberação de recursos financeiros destinados à área da infância e juventude (Asinelli-Luz, 2007).

Darlan (2000) destaca que pela legislação anterior - representada pelo Código de Menores - toda a ausência de políticas públicas fazia com que a vítima fosse tratada como responsável pela violência. No entanto, observa-se que a mudança da lei para a doutrina da proteção integral ainda tem muito a ser cumprida e aplicada na prática.

Corroborando com esta posição, Souza (2007) afirma que:

\begin{abstract}
As contradições sociais existentes na sociedade brasileira estão cada vez mais acentuando as condições de marginalidade da população, pois estas condições se tornam úteis para a manutenção do sistema vigente. Desta forma, quando crianças e adolescentes estão inseridos neste contexto, não possuindo recursos de sobrevivência, e vivendo em condições de carências em níveis: social, econômico, cultural, percebese que, mesmo existindo uma lei específica para este segmento da população, e esta garantir a Proteção Integral, ainda há um distanciamento ente a lei existente, e a garantia dos direitos expressos na mesma (p. 256-257).
\end{abstract}

Nesse sentido, pode-se novamente citar o Panorama Nacional sobre a execução das medidas socioeducativas de internação (Conselho Nacional Justiça, 2012), quando aponta os dados referentes às duas instituições de fundamental importância para a formação e o desenvolvimento dos adolescentes: família e escola. A respeito das relações familiares, a maioria dos adolescentes entrevistados não foi criada por seu pai e mãe em conjunto, sendo $43 \%$ criados somente pela mãe, $4 \%$ apenas pelo pai e 17\% pelos avós. No que se refere à escolarização, $57 \%$ dos entrevistados não frequentavam mais a escola antes de ingressar na unidade e $87 \%$ dos adolescentes não concluiu o ensino fundamental. Vale destacar que a idade média do total de adolescentes em questão é de 16,7 anos, portanto a defasagem da escolaridade é bem significativa.

Darlan (2000) destaca que a negligência do poder público, da família e da sociedade em geral acaba reproduzindo um clima de violência no qual a população infanto-juvenil vive sob coação irresistível. O autor analisa que toda ação e toda falta de ação destas instituições é no sentido de criar esses jovens sem possibilitar qualquer outra forma de sobrevivência que não seja o envolvimento com a prática de atos ilícitos. Dessa forma, estes indivíduos estão sendo condenados pela letra da própria lei, que na verdade deveriam estar sob égide de medidas de proteção e não sob repressão. 
Prates (2001) destaca que "em meio a esta calamitosa situação social é que crescem os nossos adolescentes, com suas características básicas de sujeitos em desenvolvimento, que estão constituindo sua identidade adulta" (p. 24). Ademais, Darlan (2000) analisa que a sociedade em geral é muito rigorosa quando cobra a responsabilidade do adolescente, mas não tem nenhum rigor quando deixa de cobrar responsabilidades dos que estão acima deste e que descumprem a lei.

Cabe aqui um apontamento em relação ao clamor pela responsabilização dos adolescentes comparado às exigências diante dos atores responsáveis pela garantia de seus direitos. Enquanto os jovens são demasiadamente cobrados por seus atos, parece que não há a mesma exigência daqueles que falham justamente na garantia dos seus direitos fundamentais cuja consequência se revela em ambientes falhos de recursos básicos e repletos de indicadores de violência.

\section{O adolescente que está em conflito com a lei}

A análise a seguir se pautará na importância em caracterizar os autores de atos infracionais através do que eles realmente são: adolescentes. Esta consideração, mais do que uma simples proposta de terminologia, pressupõe reconhecê-los como sujeitos em condição particular de desenvolvimento, possuidores de direitos e destinatários de proteção integral.

Segundo Volpi (1999), buscando a caracterização de adolescentes, em detrimento de termos estigmatizantes - tais quais: menores infratores, delinquentes, bandidos, entre outros - "a prática de ato infracional não é incorporada como inerente a sua identidade, mas vista como uma circunstância de vida que pode ser modificada" (p. 7). Esta questão é de fundamental importância ao passo que confere a conduta infracional como uma situação que pode ser passageira e com possibilidade real de mudança. Caso contrário, conforme descrito por Rigon (2012), a criminalização juvenil retira do adolescente a sua característica principal: a de um ser humano em pleno desenvolvimento físico e psíquico. Assim, faz com que seja visto exclusivamente como um criminoso ou como um potencial criminoso.

Com intuito de sustentar esta perspectiva, vale destacar os apontamentos de Winnicott (1987) a respeito da tendência antissocial. Diante de eventuais falhas ocorridas durante processo de desenvolvimento da infância e adolescência, seja pela falta de um ambiente acolhedor e seguro ou pela perda de alguma experiência positiva, o jovem pode reagir de modo a fazer com que aquele ambiente reconheça seu débito. Segundo o autor, todo ato antissocial representa um sinal de esperança. Neste caso, o indivíduo insiste em agir de modo a provocar reações dos demais a sua volta na tentativa de ressignificar as suas experiências negativas anteriores.

Portanto, fica evidente a importância de intervenções efetivas com os adolescentes que estão em conflito com a lei, especialmente através da aplicação da medida socioeducativa em conjunto com a rede de apoio familiar e comunitária. Prates (2001) expõe um posicionamento importante que vem ao encontro desta análise:

A rotulação social negativa gera consequências terríveis à pessoa "marcada". Ser diferente dos demais, por si só acarreta problemas profundos de ordem psicológica, e ser considerado indesejável pelos outros, baixa a autoestima, estimula o sentimento de revolta e dificulta a ressocialização, dentre outros problemas de séria gravidade. $O$ jovem infrator sofre com esta rotulação, sente a intolerância social, é mal visto, excluído, 
incompreendido. Não possui sequer maturidade para procurar compreender o que se passa a sua volta. A discriminação que sofre, a indiferença com que é tratado e a desconfiança, com tons de quase certeza, de que jamais se reabilitará, são demonstrações sociais que recebe diariamente, reafirmando sua condição de indesejável (p. 43).

O adolescente apresenta uma vulnerabilidade especial para assimilar os impactos projetivos de pais, irmãos, amigos e de toda a sociedade. Ou seja, é um receptáculo propício para encarregar-se dos conflitos dos outros e assumir os aspectos mais patológicos do meio em que vive. Isto é o que atualmente presencia-se quando a sociedade projeta suas próprias falhas nos chamados excessos da juventude, responsabilizando-os pela delinquência, pela aderência as drogas, entre outras problemáticas (Aberastury \& Knobel, 1981).

A adolescência é o momento em que os jovens estão adquirindo um sistema pessoal de valores e constituindo uma visão de mundo através de suas próprias concepções. Esta construção se estabelece a partir dos aprendizados advindos de experiências significativas do seu processo de desenvolvimento. No entanto, quando se considera que este jovem viveu em condições repletas de lacunas pessoais e sociais, tais quais as descritas anteriormente, qual seria seu referencial e de que forma o aplicaria sociedade?

Mas a adolescência, caracterizada pelo momento particular de transição e de formação da identidade, também pode ser encarada como uma possibilidade de mudança. Nesta perspectiva considera-se que o adolescente pode, através de seu intenso potencial de desenvolvimento e diante da apresentação de novas perspectivas, contornar sua trajetória descrita até o momento e traçar novos projetos futuros.

Finalizando, a fala de Luiz Eduardo Soares, MV Bill e Celso Athayde em sua obra "Cabeça de Porco" (Athayde, MV Bill \& Soares, 2005) que retrata com detalhes a realidade de muitos jovens brasileiros que vivem no mundo do crime, é bastante emblemática vai absolutamente ao encontro do tema abordado:

Aqui chegamos a um problema especialmente delicado. Até que ponto nós colaboramos para o agravamento da violência que gostaríamos de reduzir, quando acolhemos com empatia e compreensão aqueles sobre os quais a sociedade lança toda a culpa? Eles são muito jovens, quase sempre, e amargaram muitas rejeições ao longo da vida. Foram privados dos benefícios mais elementares da cidadania e acabaram cedendo à sedução do crime. São vítimas, também, ainda que façam outras vítimas, nos crimes que perpetram. Seria muito cínico lavar as mãos, manter as estruturas sociais como estão, projetar neles todo o mal e manda-los arder na fogueira. A violência deixaria de ser o fruto venenoso da sociedade que construímos. Nós nos sentiríamos aliviados de qualquer responsabilidade. As elites, os políticos, as instituições apontariam o dedo para os criminosos, exigindo punição e a interrupção da sangria desatada pela adoção de medidas duras. O drama coletivo do país, a tragédia brasileira da violência se resumiria a um problema de polícia. Dormiríamos com medo dos rapazes violentos e de suas armas poderosas, mas com a consciência tranquila, apaziguada, como compete aos homens de bem. Nada mais falso e hipócrita. A cidade ferve. A panela de pressão está prestes a explodir. Os alarmes já soaram. A responsabilidade é do Estado sim, é dos governantes, de todos eles, mas é também da sociedade, da cada um de nós. Não é aceitável jogar a culpa de tantas deformações e injustiças nas costas de um punhado de moleques. Por outro lado, não há soluções fáceis [...] (p. 123-124). 


\section{Considerações finais}

O intenso movimento da sociedade favorável à proposta reducionista retoma com força na conjuntura nacional. Diante deste contexto, nota-se que este posicionamento tem um caráter importante de denúncia e que não se refere à necessidade de maior responsabilização do adolescente autor de ato infracional, mas está relacionado com as diversas responsabilidades que estão sendo negadas justamente nos argumentos daqueles segmentos da sociedade que deveriam zelar pela garantia dos direitos fundamentais da infância e juventude.

As diversas ações ou falta de ações neste contexto ao longo dos séculos até os dias atuais, provocou uma cicatriz profunda da infância e juventude brasileira que se revela como a parcela mais exposta às violações de direitos pela família, pelo Estado e pela sociedade. As contradições sociais de um panorama político e econômico extremamente excludente dificulta a inclusão social desta população, assim como agrava o processo de falta de perspectivas e aumento da criminalidade.

A compreensão da sociedade diante da prática de atos infracionais cometidos por adolescentes revela sua intolerância e dificuldade em reconhecer este jovem também como um cidadão. Em contrapartida todos os condicionantes históricos e socioculturais facilitam a atribuição determinista da responsabilidade sobre o adolescente, ignorando que o ato infracional é uma problemática essencialmente social.

A maioria dos adolescentes que comete atos infracionais, antes de violar os direitos de suas vítimas, já teve muitos dos seus direitos fundamentais violados. O intuito desta reflexão não tem como objetivo excluir a responsabilidade destes jovens, mas indicar um novo olhar sobre esta questão, a partir de dados fidedignos que se aproximem da realidade em que vivem os adolescentes brasileiros.

Considerar estes jovens autores de atos infracionais a partir do que eles realmente são - adolescentes- pressupõe mais do que uma simples mudança de terminologia, assim como está sendo observada ao longo dos anos desde a promulgação do Estatuto da Criança e do Adolescente. Pressupõe reconhecê-los como sujeitos em condição particular de desenvolvimento e principalmente considerar o delito como uma circunstância da e na vida desses jovens cujo destino ainda pode ser modificado. Lançar um olhar sobre estes adolescentes que vá além do ato infracional cometido, permite observar seu imenso potencial de desenvolvimento e mudança. Apresentando-lhes novas possibilidades com base para construção de novas trajetórias, é possível crer em pequenas transformações individuais e novas perspectivas futuras.

Para tanto, é imprescindível que a sociedade reconheça que a prática de atos infracionais por adolescentes, ainda que tenha seu arbítrio, é essencialmente uma problemática social. Enquanto não forem repensadas as consequências de um contexto socioeconômico extremante desigual, todas as formas de violações dos direitos fundamentais da infância e adolescência e a rotulação negativa lançada sobre estes jovens, com mesmo rigor que se promove a responsabilização dos adolescentes, a mudança social tão esperada por todos parece ainda mais complexa e distante.

Há necessidade urgente do poder público investir na assistência à população infanto-juvenil garantindo o cumprimento efetivo dos dispositivos preconizados pela doutrina da proteção integral; das instituições familiar e escolar se comprometerem no 
processo de desenvolvimento das suas crianças e adolescentes; e da população repensar sua concepção diante da prática de atos infracionais.

Caso contrário, a redução da idade de responsabilização penal permanecerá como uma solução simples e muito atraente, disfarçando todas as responsabilidades daqueles que deveriam se implicar incondicionalmente com a garantia dos direitos das crianças e adolescentes brasileiros.

\section{Referências}

Aberastury, A. \& Knobel, M. (1981). Adolescência normal: um enfoque psicanalítico. Porto Alegre: Artmed.

Andi/Comunicação e Direitos (2012). Secretaria de Direitos Humanos da Presidência da República. Adolescentes em conflito com a lei: guia de referência para a cobertura jornalista. Brasília. Recuperado em 28 de maio, 2014, de http://www.andi.Org..br/infancia-e-juventude/publicacao/adolescentes-em-conflitocom-a-lei-guia-de-referencia-para-a-cobertu

Arantes, E. M. de M. (2013). Sobre as propostas de redução da maioridade penal. In Conselho Federal de Psicologia, Redução da Idade Penal: Socioeducação não se faz com prisão. Brasília: CFP.

Asinelli-luz, A. (2007). Do direito à educação, à cultura, ao esporte e ao lazer. In Lavoratti, C. (Org.), Programa de capacitação permanente na área da infância e da adolescência: o germinar de uma experiência coletiva. Ponta Grossa: Ed UEPG.

Athayde, C., MV B. \& Soares, L. E. (2005). Cabeça de porco. Rio de Janeiro: Objetiva.

Bocco, F. (2009). Cartografias da infração juvenil. Porto Alegre: ABRAPSO SUL.

Brasil (2013). Plano Nacional de Atendimento Socioeducativo: Diretrizes e eixos operativos para o SINASE. Brasília: Secretaria de Direitos Humanos da Presidência da República.

Brito, L. M. T. de (2013). Redução da maioridade penal, pra quê? In Conselho Federal de Psicologia, Redução da Idade Penal: socioeducação não se faz com prisão. Brasília: CFP. 
Conselho Federal de Psicologia (2013). Redução da Idade Penal: socioeducação não se faz com prisão. Brasília: CFP.

Conselho Nacional de Justiça (2012). Panorama Nacional de Execução de Medidas Socioeducativas de Internação - Programa Justiça ao Jovem. Recuperado em 21 de julho, 2014, de http://www.cnj.jus.br/images/pesquisasjudiciarias/Publicacoes/panorama_nacional_doj_web.pdf

Costa, L. C. da \& Madalozzo, S. S. N. (2007). Política Social: o atendimento de crianças e adolescentes no Brasil. In Lavoratti, C. (Org.), Programa de capacitação permanente na área da infância e da adolescência: o germinar de uma experiência coletiva. Ponta Grossa: Ed UEPG.

Darlan, S. (2000). A criança e o adolescente: a exclusão da vida social, criminalização e subalternização dos excluídos e oprimidos. In Brito, L. M. T. de (Coord.), Responsabilidades: ações socioeducaivas e políticas públicas para a Infância e Juventude no Estado do Rio de Janeiro. Rio de Janeiro: EdUERJ.

Macedo, R. C. M. de (2008). O Adolescente Infrator e a Imputabilidade Penal. Rio de Janeiro: Lumen Juris.

Marques, J. (2000). A mídia e a construção do imaginário popular. In Brito, L. M. T. de (Coord.), Responsabilidades: ações socioeducativas e políticas públicas para a Infância e Juventude no Estado do Rio de Janeiro. Rio de Janeiro: EdUERJ.

Melo, D. L. B. de \& Cano, I. (Orgs.) (2012). Índice de homicídios na adolescência: IHA 2009-2010. Rio de Janeiro: Observatório de Favelas.

Prates, F. C. (2001). Adolescente Infrator: a prestação de serviços à comunidade. Curitiba: Juruá.

Real, F. G. V. C. \& Conceição, M. I. G. (2013). Representações Sociais de Parlamentares Brasileiros sobre a Redução da Maioridade Penal. Psicologia: Ciência e Profissão, 33(3), 656-671.

Rigon, R. A. (2012). Delinquência Infanto-juvenil: uma abordagem desenvolvimentista em criminologia. Curitiba: Juruá. 
Saraiva, J. B. C. (1999). Adolescente e ato infracional: garantias processuais e medidas socioeducativas. Porto Alegre: Livraria do Advogado.

Souza, P. de (2007). 0 ato infracional e as medidas socioeducativas previstos no Estatuto da Criança e do Adolescente. In Lavoratti, C. (Org.), Programa de capacitação permanente na área da infância e da adolescência: o germinar de uma experiência coletiva. Ponta Grossa: Ed UEPG.

Teixeira, M. de L. T. (2013). Redução da idade penal... Mais uma vez! In Conselho Federal de Psicologia, Redução da Idade Penal: socioeducação não se faz com prisão. Brasília: CFP.

Volpi, M. (1999). 0 adolescente e o ato infracional. (3a ed). São Paulo: Cortez.

Volpi, M. (2001). Sem liberdade, sem direitos: a experiência de privação de liberdade na percepção dos adolescentes em conflito com a lei. São Paulo: Cortez.

Winnicott, D. (1987). Privação e Delinquência. São Paulo: Martins Fontes.

Recebido / Received: 10/11/2015

Aprovado / Approved: 15/12/2015 